\title{
LER AS IMAGENS DOS DESENHOS ANIMADOS: UM HÁBITO A ENSINAR E APRENDER NA ESCOLA
}

\author{
Carla Borges de Andrade ${ }^{1}$
}

\begin{abstract}
Resumo: Num mundo dominado pelas imagens e informações, muito mais que apreciar essa linguagem artístico-imagética, faz-se necessário ensinar desde a escola a ler efetivamente esses textos pictóricos. Uma maneira atraente aos alunos de se fazer isso é utilizando em sala de aula os desenhos animados. Este texto objetiva fomentar a discussão a respeito do ensino da leitura de imagens e orientar os docentes acerca da utilização dos desenhos animados para que esta prática realmente se torne efetiva nas escolas.
\end{abstract}

Palavras-Chave: Leitura de imagens, Mídia, Desenho animado, Ensinoaprendizagem.

Abstract: In a world dominated by images and information, much appreciate that this language-artistic imagery, it is necessary to teach from school to read these texts effectively pictorial. An appealing way for students to do this is using classroom cartoons. This text aims to foster discussion about the teaching of reading images, and guide teachers on how to use cartoon for this practice to become really effective in schools.

Keywords: Reading images; Media; Cartoon; Teaching and learning.

\section{LEITURA DE IMAGENS}

Muito se fala sobre fazer leitura de mundo, como forma educativa de se formarem cidadãos críticos, conscientes de seu papel social. Entretanto, nunca se viveu uma época tão dominada pelas imagens: elas estão por todos os lugares, associando-se, agregando valor ou mesmo substituindo outras formas de linguagem e comunicação social.

Nômades em nossas próprias casas, capturamos imagens, muitas vezes sem modelo, sem fundo, cópias de cópias, no cruzamento de inúmeras significações. Imagens para deleitar, entreter, vender, que nos dizem o que vestir, comer, aparentar, pensar (SARDELICH, 2006, p. 452).

$E$, nesse contexto, a leitura de mundo inclui sobremaneira a leitura de imagens, posto que ambas, em certos momentos, chegam a se confundir em seus significados, tornando-se similares.Se assim o é, da mesma forma

1 Departamento de Saúde, Universidade Estadual de Feira de Santana (UEFS); Mestre em Desenho, Cultura e Interatividade (UEFS); Grupo de Pesquisa e Extensão: Artes do Corpo. Grupo de Pesquisa: História da Disciplina de Desenho, a partir da Produção de Livros Didáticos. Endereço eletrônico: carlabajs@hotmail.com. 
que os professores devem se preocupar em ensinar seus alunos a lerem o mundo, devem também incluir em suas preocupações a formação imagética dos estudantes, ensinando-os a lerem as imagens, educando (o que não quer dizer homogeneizando) seu olhar para que alcancem os sentidos reais das coisas que os cercam imageticamente.

Esta, mais que uma recomendação, é uma necessidade que urge atualmente, como afirma Sardelich (2006, p. 451): "Em nossa sociedade contemporânea discute-se a necessidade de uma alfabetização visual, que se expressa em várias designações, como leitura de imagens e compreensão crítica da cultura visual". Alfabetizar visualmente, ou seja, educar imageticamente "é, sem dúvida, fazer ver mais, ver além das aparências que vestem as coisas e os discursos, o que se processa através da compreensão das relações produtoras de significação" (PILLAR, 2008, p. 6).

Ensinar a ler imagens não significa apontar para onde os alunos devem olhar, mas ajudá-las a avançarem em questionamentos e entendimentos do que está nas entrelinhas, do que nem sempre é visível ou dito, mas que se mantém como mensagem subliminar da própria imagem midiática.

A mídia contagia e contamina nossa percepção de mundo, nossa apreensão visual e nossos processos de criação. Contagia porque ao entrar em contato com ela, na captura ativa e sensível de sentidos, nos projetamos e deslizamos em seus produtos. Mais do que ser objeto de leitura, a mídia - revistas, jornais, televisão - nos constitui, contamina nosso modo de ver, pensar e sentir (PILLAR, 2007, p. 1).

Embora seja emergencial contemporaneamente que se ensine/aprenda a ler imagens, desde os anos 70 do séc. XX já se utilizava esse termo, conceituando-se a prática da leitura de imagens a partir de diferentes matrizes teóricas e referenciais:

A expressão leitura de imagens começou a circular na área de comunicação e artes no final da década de 1970, com a explosão dos sistemas audiovisuais. Essa tendência foi influenciada pelo formalismo, fundamentado na teoria da Gestalt, e pela semiótica. Na psicologia da forma, a imagem constituía percepção, já que toda experiência estética, seja de produção ou recepção, supõe um processo perceptivo. A percepção é entendida aqui como uma elaboração ativa, uma complexa experiência que transforma a informação recebida. Na medida em que a imagem passa a ser compreendida como signo que incorpora diversos códigos, sua leitura requer o conhecimento e a compreensão desses códigos (SARDELICH, 2006, p. 453). 
Ou seja, a leitura de imagens só se efetiva quando seus signos têm seus significados também conhecidos, ou melhor, ensinados/aprendidos. Neste processo, orienta-se o exercício dos olhares conotativo e denotativo sobre a imagem a ser lida: por denotação se entenda o "significado entendido "objetivamente", ou seja, o que se vê na imagem "objetivamente", a descrição das situações, figuras, pessoas e ou ações em um espaço e tempo determinados". Já a conotação designa as"apreciações do intérprete, aquilo que a imagem sugere e/ou faz pensar o leitor" (SARDELICH, 2006, p. 456).

Dentre os elementos denotativos, Pillar (2007, p. 4) destaca que "o que primeiro captura a atenção das crianças é, então, o plano de expressão com suas qualidades sensíveis: a música, a cor, a caracterização dos personagens" das imagens que lhes são apresentadas, as quais provêm, principalmente, dos desenhos animados de televisão, aos quais assistem diariamente.

\section{DESENHOS ANIMADOS: IMAGENS A SEREM LIDAS}

Se é verdade que se pretende mesmo formar cidadãos críticos, conscientes e pensantes, os desenhos animados, enquanto mídia, podem contribuir para o alcance desse objetivo, uma vez que "a mídia contagia e contamina nossa percepção de mundo, nossa apreensão visual e nossos processos de criação" (PILLAR, 2007, p. 665). Dessa forma, pode-se afirmar que os desenhos animados ampliam a capacidade de leitura de mundo dos alunos, pois influenciam diretamente seu "modo de ver, pensar e sentir". Para a autora, enquanto assistem aos desenhos, as crianças os leem e atribuem-lhes sentidos e significados, ou seja, estão lendo imagens, estão lendo o mundo, o seu mundo:

Dentre as produções televisivas direcionadas às crianças, os desenhos animados ocupam grande parte desta programação, seja inseridos em programas infantis, seja exibidos em horários especiais. Compreender este texto sincrético implica identificar as linguagens que o compõem e como elas se articulam, interagem, criando uma rede de significações (PILLAR, 2007, p. 3).

Por exemplo, cita-se o desenho dos Thundercats, que realmente orienta como se deve agir para ter "uma visão além do alcance", como dizia a personagem Lion, no sentido do exercício da liderança, a qual não se dá por imposições arbitrárias, mas por meio do diálogo, do reconhecimento do que é certo ou errado, bem como do que é melhor para o coletivo. Outro exemplo interessante é o desenho dos Smurfs, que amplia a visão dos seus 
telespectadores em relação à estrutura, organização e manutenção da vida em comunidade.

Portanto, os desenhos animados (da mesma forma que outras possibilidades imagéticas) podem e devem adentrar o ambiente escolar a fim de propiciar o ensino/aprendizagem da leitura de imagens, uma vez que já são familiares ao universo infantil, e por promoverem outras leituras que ampliam a capacidade de abstração dos alunos, sua criatividade, criticidade e argumentação (ANDRADE, 2012). O contato com essas imagens e suas leituras faz com que os alunos passem "a se interessar por sua interpretação, procurando sugerir significados em suas próprias produções [...] e fazer afirmações através de suas experiências" (SARDELICH, 2006, p. 463), as quais geralmente estão ligadas ao universo televisivo dos desenhos animados. Portanto,

considero que os meios de comunicação de massa "são o instrumento de um fantástico devaneio social, a tal ponto que a humanidade, talvez nunca tivesse sonhado melhor do que neste século $X X$, nunca tivesse conhecido, graças a ele, oferta de imaginário mais rica e mais diversificada". Nesse sentido, declaro que a televisão e os desenhos animados adentram o imaginário infantil - e por que não dizer o adulto também? - permitindo uma saída do real para irromper no mundo onde tudo é possível e permitido, através de suas aparentemente agradáveis imagens (ANDRADE, 2012, p. 42).

Agradáveis e sedutoras imagens! Isso inclusive já fora comprovado em diferentes estudos (ANDRADE, 2012; FUSARI, 1985), que os desenhos animados possuem elementos de seduçãoque "contribuem significativamente para a formação das crianças que os assistem, seja em casa ou em outros espaços como a escola ou o cinema" (ANDRADE, 2012, p. 44). Dentre esses elementos de sedução, destacam-se:

dinamismo visual (tanto do tempo quanto do movimento); grafismo; simplificação, deformação e caricatura; criatividade na superação e alteração das leis físicas; interpretação criativa dos movimentos naturais dos seres e das formas da natureza (FUSARI, 1985 apud ANDRADE, 2012, p. 44).

O desenho animado também se configura como importante elemento de atração da atenção dos menores, apresentando-Ihes por horas seguidas valores, ideologias e comportamentos que interferem diretamente no seu processo de compreensão do meio que os cerca. Ao reunir em si elementos de sedução tais como cor, imagem, som e movimento, os desenhos animados aproximam os telespectadores das diferentes linguagens, conduzindo-os a sua completa apreensão: "no desenho animado, o sistema visual 176 Número temático: Desenho e Educação: Cultura Visual e Cidade. A Cor das Letras - UEFS, n. 
acolhe as linguagens verbal escrita, imagética, cenográfica, gestual e a moda; e o sistema sonoro abarca as linguagens da música, os ruídos e o verbal oral" (PILLAR, 2007, p. 665), ampliando as formas de compreensão do mundo que se manifesta sob diferentes tipos de linguagens. Boynard (2002, p. 283), amplia essas considerações quando declara que o desenho animado é importante por "facilitar o desenvolvimento da personalidade e estimular um canal sadio na resolução dos problemas cotidianos" através de linguagens próprias e atraentes que obrigam "a formação de novos modos de compreender" o mundo. Linguagens estas que se verificam na "identificação com personagens de desenhos, seus comportamentos, características emblemáticas, mesmo que simplistas de bom e mau, certo e errado, mal e bem."

Assim sendo, ao se disponibilizar um desenho animado para que a criança assista, deve-se ter o cuidado de não limitar as indagações que a mesma poderá fazer acerca de eixos outros que extrapolam o da temática abordada, bem como se deve até incentivar o olhar múltiplo, interdisciplinar e intertextual da mesma a fim de estimular o desenvolvimento de seu pensamento crítico, o qual deve ser, sobretudo, global. Ao assistir a desenhos animados, a criança amplia seus horizontes, faz transposições (ainda que rudimentares) e estabelece relações intra e interpessoais, que poderá ou não colocar em prática no seu dia-a-dia.

A "cultura da criança" (MARCELINO, 2000, p. 36) é construída a partir do lúdico - jogos, brinquedos, brincadeiras... - e "se fundamenta essencialmente no jogo simbólico ou faz-de-conta, que resulta do próprio imaginário infantil e que tem na inventividade sua principal característica" (idem). Nesse sentido, "os desenhos animados são, em geral, colocados como entretenimento, como diversão infantil. Mas esse divertimento não é vazio de conteúdos simbólicos [...]: político, cultural, social, religioso, econômico" (SIQUEIRA, 2002, p. 110).

Posto isso, é consenso na literatura consultada que os estímulos a essa cultura geral, à imaginação e à habilidade de inventar efetivamente contribuam para o desenvolvimento educacional da criança. E os desenhos animados seriam exemplos desses estímulos, posto que" as crianças não se contentam em apenas ver os desenhos ou seriados e guardarem em suas memórias" (PILLAR, 2008, p. 4), mas procuram se colocar no lugar das personagens que mais lhes agradam e motivam.

O princípio da inventividade sinalizado acima imediatamente remete ao conceito de criatividade. Importante meta perseguida pela educação, a 
criatividade das crianças precisa ser aflorada para que certas aprendizagens aconteçam, quer de caráter conceitual, procedimental ou atitudinal. Enquanto assiste ao desenho animado, a criança busca praticarou exercitar a sua" criatividade, podendo imaginar outros fatos idênticos" (NORBERTO, 2005, p. 26) aos que assistia, recriando-oscomo é hábito no meio infantil. Afinal, se não todas, boa parte das crianças faz o mesmo com os brinquedos que ganham: quebram ou desmontam para dar-lhes nova significação, nova utilização e, assim, construírem as próprias brincadeiras, reconstruindo-os. Para tanto, utilizam-se de suas múltiplas capacidades ou inteligências. Novamente os desenhos animados poderiam entrar em cena (no caso da escola, como recursos didáticos de excelência), pois as crianças, quando lhes assistem, praticam a oralidade, a escrita, a memória, a musicalidade e outras inteligências.

Não se pode deixar de abordar também a questão da diversão, da ludicidade inerente a esses desenhos. As animações podem promover grande interesse junto aos menores, motivando-os à aprendizagem, à descoberta e à própria iniciativa de experimentação de coisas novas,

fazendo com que a criança queira cada vez, aprender mais. Aqui que está a verdadeira aprendizagem. A criança aprende sem sequer se aperceber de que está a aprender. A criança é assim educada de forma divertida e pedagógica (NORBERTO, 2005, p. 26),

o que origina um ser social interessante e criativo, que traça metas e busca alcançá-las através do conhecimento que vai construindo paulatinamente, à medida que assiste a mais e mais desenhos. Até porque, assim como os noticiários, os desenhos animados da televisão também trazem em suas narrativas "numerosos conhecimentos que a criança ainda não questionou levando-a a pensar noutros temas que ainda sequer tinha pensado, baseando-se depois, nos modelos da televisão para aprender a agir no mundo" (NORBERTO, 2005, p. 20). Essa aprendizagem se dá através da observação, imitação e interação que a criança estabelece com as personagens dos desenhos, consigo mesma e com os demais atores de seu círculo social.

Assim, os desenhos animados trazem respostas aos mais intrigantes questionamentos de criança, numa linguagem acessível, permitindo que os sentimentos mais íntimos aflorem e tantas certezas se construam a cada novo episódio - o que nem sempre é obtido no cotidiano escolar, conforme declara Marcel Bluwal (1977 apud NORBERTO, 2005, p. 6): "a escola não é a única entidade a dar respostas às questões que a vida levanta: o quadro 
familiar dá respostas, a rua dá respostas. E a televisão dá respostas". E ouso aqui dizer que, muitas vezes, essas respostas dadas pelos desenhos animados da televisão aos questionamentos infantis são percebidas pelas crianças com maior clareza e perspicácia, uma vez que são imbuídas de criatividade, cor, som, graça e vocabulário acessível - elementos de sedução e fácil apreensão, enquanto que, na escola, não em poucas oportunidades, o excesso de linguagem técnica-científica do meio adulto frequentado pelo professor favorece uma distância tantas vezes intransponível pelos pequenos e, consequentemente, suas dúvidas permanecem, posto que não se alcançaram respostas.

Enquanto atividade de entretenimento, os desenhos animados favorecem também que se externem os sentimentos mais puros das crianças em relação a si mesmas e aos outros com quem convivem - e, portanto, em relação à própria imagem corporal e as dos outros. "O entretenimento, nesse sentido, promoveria a liberação de angústias e de contradições sociais" (SIQUEIRA, 2002, p. 114) e também favoreceria o processo de construção da imagem corporal através da ampliação ou diminuição da autoestima.

O desenho animado é, portanto, um importante meio de comunicação entre a criança e a sociedade e forte exemplo de representação simbólica da criança, pois a partir dele a mesma expressa e reflete suas ideias, sentimentos, percepções e descobertas corporais. Nesse sentido é que afirmo que os desenhos animados atuam como comunicadores de imagens corporais.

O desenvolvimento do potencial criativo na criança, seja qual for o tipo de atividade em que ela se expresse, é essencial ao ciclo inato de crescimento. É então fundamental preencher o imaginário das crianças com imagens cotidianas recheadas de significados poéticos, possibilitando um contato mais sensível com os ambientes em que elas vivem - natural ou construído - através dos sentidos, como a audição e a visão, partindo de um autoconhecimento para o conhecimento do outro e de si mesmas:"O desenho animado enquanto 'fábrica de imagens' conjuga elementos oriundos do domínio da observação sensível do real e da capacidade de imaginar e projetar, vontades de significar" (GOLDBERG, YUNES e FREITAS, 2005, p. 102) em seu corpo aquilo a que assistiu. E mais, "o desenho configura um campo minado de possibilidades, confrontando o real, o percebido e o imaginário. A observação, a memória e a imaginação são as personagens que flagram essa zona de incerteza: o território entre o visível e o invisível". 


\section{LER IMAGENS DE DESENHOS ANIMADOS NA ESCOLA}

Tendo tecido estas considerações, não acredito tratar-se de exagero a sugestão que ora faço de inserir os desenhos animados na escola, enquanto recurso pedagógico para o ensino-aprendizagem de diferentes conteúdos. Isso porque, para além de todas as contribuições sinalizadas até então, a utilização dos desenhos animados configuraria a valorização e o reconhecimento de um dos importantes saberes das crianças, e a permissão para a livre expressão das mesmas a partir daquilo que lhes é próprio, expressão tal que se dá em, com e por meio de seus corpos.

Assim sendo, todo o processo escolar se torna mais significativo e prazeroso, pois, conforme sugere Garcia (2002), as crianças começam a se interessar mais por aprender o que os professores tanto têm a lhes ensinar, tal como a leitura e a escrita. Nas palavras do autor, historicamente, o professor que resolveu inovar em sua prática docente fazendo adentrar no ambiente escolar aquilo que tanto interessa ao público infantil - como seria o caso dos desenhos animados - consequentemente "mudou o clima da sala de aula, o prazer teve permissão para entrar e as possibilidades de prazer se ampliaram. Valorizadas no que já sabiam, as crianças foram encorajadas a aprender o que ainda não sabiam" (GARCIA, 2002, p. 12). Quero dizer com isso, que não se trata de encarar os desenhos animados na escola apenas como estimuladores da aprendizagens de certos conteúdos, mas que eles são conteúdos em si mesmos a serem ensinados, imagens a serem lidas, seja no que se refere à mensagem (científica, histórica, narrativa, sociológica, antropológica, ideológica...), à técnica de animação, ao estilo gráfico, à sonoridade, enfim, há inúmeras possibilidades de aproveitamento dos desenhos enquanto conteúdos de ensino-aprendizagem.

Destarte, quando se propõe a trabalhar com a leitura de imagens dos desenhos animados, o professor deve perceber que já não lhe cabe mais o papel de "perguntar o que as/os educandas/os não sabem e propor-se a ensinar-lhes, e sim o que já sabem e como é possível ampliar as conexões, para que, juntos, possam organizar outros discursos com os saberesmosaico que todos possuem" (SARDELICH, 2006, p. 466). Assim, caracterizase um trabalho conjunto de ampliação das possibilidades de aprendizagem de todos os envolvidos, inclusive do professor, posto que os alunos também têm muito a ensinar. 
E para além do processo de educação formal, dito escolar, acrescento que os desenhos animados devem permear o desenvolvimento da educação doméstica, familiar, já que é em casa que, geralmente, ocorre o encontro com o maior número e tipologia de desenhos animados. Assim, caberia aos pais a análise dos desenhos que permitem que seus filhos assistam, dialogando sobre e por meio deles, a fim de que se ensine a ler imagens ainda dentro de casa.

\section{REFERÊNCIAS}

ANDRADE, Carla Borges. Infâncias seduzidas pelos desenhos animados. Feira de Santana: EDUEFS, 2012.

BOYNARD, Ana Lúcia S. Desenho animado e formação moral: influências sobre crianças dos 4 aos 8 anos de idade. In: Atas do III SOPCOM, VI LUSOCOM e II IBÉRICO, v. IV, p. 283-290, ago. 2002.

GARCIA, Regina Leite. (Org.). O corpo que fala dentro e fora da escola. Rio de Janeiro: DP\&A, 2002.

GOLDBERG, Luciane G.; YUNES, Mạ Angela M.; FREITAS, Jsé V. O desenho infantil na ótica da ecologia do desenvolvimento humano. Psicologia em Estudo. Maringá, v. 10, n. 1, p. 97-106, jan./abr. 2005

MARCELLINO, Nelson Carvalho. Estudos do lazer: uma introdução. 2. ed. Campinas: Autores Associados, 2000.

NORBERTO, Telma Alexandra Hilário. Os desenhos animados e o comportamento das crianças. (Monografia) Escola Superior de Educação. Instituto Politécnico Jean Piaget, dez. 2005.

PILLAR, Analice Dutra. Visualidade contemporânea: interação de linguagens e leitura. In: Anais. FACED/UFRGS. 2007. Disponível em: www.anpap.org.br/anais/2007. Acesso em: 6 dez. 2012.

SARDELICH, Maria Emilia. Leitura de imagens, cultura visual e prática educativa. Cadernos de Pesquisa, v. 36, n. 128, p. 451-472, maio/ago. 2006.

SIQUEIRA, Denise da Costa Oliveira. Ciência e poder no universo simbólico do desenho animado. Ciência e Público, p. 108-120, 1998. Disponível em: www.casadaciencia.ufrj.br. Acesso em: 3 mar. 2009. 
